\title{
PERSEPSI MAHASISWA, DOSEN DAN BIDAN PEMBIMBING TENTANG MODEL PEMBELAJARAN KLINIK KEBIDANAN YANG IDEAL
}

\author{
Yanti, Ova Emilia, Mora Claramita \\ * Program D-III Kebidanan, Stikes Estu Utomo. Boyolali \\ ** Program Studi S2 IKM,
}

\begin{abstract}
Background: A large number graduates of midwife even now accompanied with low competency isues in associated with quality of clinical learning. Now implementation of clinical learning with caseload model has problems. Clinical learning model in clinical practice that student, teacher and clinical midwife experienced provide greater insight to develop an effective clinical teaching strategy in midwifery education.

Aim: The main objective of this study was to investigate student midwife, teacher and clinical midwife' insight about an ideal clinical learning model in midwifery education.

Method: A qualitative study by Focus Group Discussion (FGDs). By selected randomly, this study was conducted 32 from 76 final year midwifery students at Estu Utomo Boyolali Midwifery Academy, 14 lecturer and 13 clinical midwife who involve in Estu Utomo Boyolali Midwifery Academy clinical practice program at 2013-2014. There are 4 groups of student midwife, 2 groups of lecturer and 2 groups of clinical midwife. FGDs were arranged in 3 session differently between students, lecturer and clinical midwife. FGDs were facillitated by researcher and 3 research assistant. Data were analyzed using Atlas. Ti 6.1 software to support the coding process and identifying the main categories from verbatim transcripts.

Results and Discussion: Six themes emerged from the focus group data, "student caseload", "duration of clinical practice", "clinical placement", "clinical mentorship", "documentation", and "clinical assessment". From the sixth themes, demonstrated that an ideal clinical learning model in midwifery education to design preparation clinical learning should consider about that components. An ideal clinical learning model in midwifery education should give priority to quality than quantity especially the sugest to decrease student caseload.

Conclusion: This study showed that midwife student, teacher and clinical midwife suggest that clinical learning model should give priority to quality than quantity to gain midwifery care competence. Clinical learning model therefore applied with student caseloading that each student have different need. They are suggest that midwifery clinical learning should be consistent with the midwifery care philosophy "women center care" that provide midwifery continuity of care.
\end{abstract}

Keywords: midwifery clinical learning, midwifery care, clinical practice, student and midwife perspective..

\section{ABSTRAK}

Latar belakang: Banyaknya lulusan bidan saat ini dibarengi dengan isu kurangnya kompetensi lulusan yang sering dikaitkan dengan kualitas pembelajaran klinik. Pembelajaran klinik dengan model beban kasus saat ini mengalami berbagai kendala dalam implementasinya. Pengalaman dalam implementasi model pembelajaran klinik yang dirasakan oleh mahasiswa, dosen maupun bidan pembimbing klinik memberikan kontribusi terbesar untuk pengembangan strategi pembelajaran klinik yang efektif dalam pendidikan kebidanan.

Tujuan: Untuk menggali pendapat mahasiswa kebidanan, dosen dan bidan pembimbing tentang model pembelajaran klinik kebidanan yang ideal untuk pencapaian kompetensi asuhan kebidanan oleh mahasiswa.

Korespondensi: yantipurnomo05@gmail.com dan yanti_sub@yahoo.co.id 
Metode: Penelitian kualitatif melalui diskusi kelompok terfokus (DKT). Dengan menyeleksi secara acak, penelitian ini melibatkan 32 orang dari 76 mahasiswa tingkat akhir, 14 dosen dan 13 bidan pembimbing klinik yang terlibat dalam program praktik klinik Akademi Kebidanan Estu Utomo Boyolali tahun 2013-2014. Ada 4 kelompok mahasiswa, 2 kelompok dosen dan 2 kelompok bidan pembimbing klinik. DKT dilakukan melalui 3 sesi yang berbeda antara kelompok mahasiswa, dosen dan bidan pembimbing. DKT difasilitasi oleh peneliti sendiri dibantu 3 orang tenaga penelitian. Analisis data menggunakan software Atlas. Ti 6.1, untuk melakukan proses koding dan kategori dari transkrip verbatim.

Hasil dan Pembahasan: Ada 6 tema yang dihasilkan dari DKT untuk menggali persepsi mahasiswa, dosen maupun bidan pembimbing tentang model pembelajaran klinik kebidanan yang ideal yaitu : "target kasus", "durasi praktik klinik", "penempatan klinik", "bimbingan klinik", "dokumentasi laporan", dan "penilaian praktik klinik". Dari ke-6 tema yang muncul, menunjukkan bahwa model pembelajaran klinik kebidanan yang ideal sebaiknya memperhatikan komponen-komponen tersebut yang dirancang dengan baik dalam persiapan praktik klinik. Model pembelajaran klinik kebidanan yang ideal diharapkan lebih mengutamakan kualitas dibanding kuantitas terutama usulan untuk menurunkan target kasus.

Kesimpulan: Hasil penelitian ini menunjukkan bahwa mahasiswa, dosen maupun bidan pembimbing klinik mengusulkan model pembelajaran klinik yang lebih mengutamakan kualitas daripada kuantitas untuk mencapai kompetensi asuhan kebidanan. Mereka mengusulkan agar pembelajaran kinik kebidanan dengan menggunakan model beban kasus yang disesuaikan kebutuhan masing-masing mahasiswa, yang sejalan dengan filosofi kebidanan dengan memfasilitasi asuhan kebidanan berkelanjutan.

Kata Kunci: pembelajaran klinik kebidanan, asuhan kebidanan, praktik klinik, persepsi mahasiswa dan bidan pembimbing klinik.

\section{LATAR BELAKANG}

Pengalaman praktik klinik menyediakan kesempatan belajar yang memungkinkan pencapaian kompetensi keterampilan klinik keperawatan/kebidanan sebagai hasil pembelajaran. ${ }^{1}$ Pembelajaran klinik merupakan suatu cara untuk membantu peserta didik menerapkan pengetahuan mereka pada problem praktis lapangan. ${ }^{2}$ Dalam pembelajaran klinik peserta didik dapat menerapkan ilmu asuhan keperawatan pada kasus-kasus yang ditangani serta mendapatkan kesempatan untuk mempraktekkan teori-teori keterampilan yang telah dipelajari. Semakin banyak jenis kasus yang ditemui di klinik, peserta didik akan semakin banyak mendapatkan pengalaman untuk menerapkan ilmu serta melatih keterampilan yang mendasari peningkatan kemampuan profesionalnya. $^{3}$

Praktik klinik merupakan bagian integral dalam kurikulum kebidanan. Selama praktik klinik mahasiswa kebidanan menerapkan teori, mengembangkan keterampilan dan membangun kompetensi mereka ${ }^{4,5}$ serta mengembangkan identitas profesional. ${ }^{5,6}$ Selama praktik klinik mahasiswa kebidanan belajar secara tradisional melalui sebuah hubungan siswa-pembimbing (student-preceptor relationship). ${ }^{6}$
Beberapa faktor perlu diperhitungkan saat akan merencanakan program kegiatan praktik klinik. Menurut Schweek dan Gebbie, praktek klinik merupakan "the heart of the total curriculum plan". ${ }^{3} \mathrm{Hal}$ ini berarti unsur yang paling utama dalam pendidikan keperawatan adalah bagaimana proses pembelajaran dikelola di lahan praktek. Kerr dalam Quinn menyata-kan bahwa kurikulum mempengaruhi pendidikan kebidanan dengan mengakomodasi prinsip-prinsip penting untuk perencanaan pendidikan dalam sebuah format yang mampu diterjemahkan dalam kegiatan praktik klinik. ${ }^{7}$ Dalam merencanakan persiapan praktik klinik bagi siswa, perlu diperhitungkan struktur maupun lama praktik klinik serta pengaruh dari model pembelajaran saat ini terhadap pengalaman belajar siswa. ${ }^{8}$

Kurikulum berdasarkan pandangan baru kebidanan ${ }^{9}$, menekankan pada sebuah perspektif bahwa bidan adalah pemberi asuhan dasar dan hubungan bidan-perempuan dalam bentuk kemitraan yang tidak terstruktur yang terpelihara melalui hubungan yang berkelanjutan. Pandangan kebidanan yang baru ini secara ideologi selaras dengan tujuan dari kurikulum pendidikan bidan 
maupun standar kompetensi kebidanan yang digunakan untuk menilai siswa.

Model pembelajaran praktik klinik kebidanan yang diterapkan pada Program Pendidikan DIII Kebidanan di Indonesia selama ini adalah model beban kasus, dengan memberikan sejumlah target kasus kepada mahasiswa. ${ }^{10,11}$ Dalam struktur kurikulum DIII Kebidanan $^{9}$, model asuhan kebidanan yang diterapkan dalam pencapaian target kasus dilaksanakan melalui tiga kali praktik klinik kebidanan (PKK) selama masa studi, yang terdistribusi pada tiga semester (III, IV \& V). Target kompetensi pada masing-masing tahap PKK disesuaikan dengan mata kuliah asuhan kebidanan yang sudah diberikan di kelas. Mahasiswa ditempatkan di lahan praktik dengan mengikuti pola alokasi praktik klinik kebidanan (8 - 10 minggu setiap semester), dengan total SKS sebesar 15 SKS atau setara 720 jam. Jumlah jam tersebut masih sangat jauh dibandingkan standar minimal ICM (1800 jam), dimana 80\% penempatan klinik pada tahun ke-tiga studi. ${ }^{12}$

Praktik dengan beban kasus membantu perkembangan siswa untuk berkesempatan bekerja secara mandiri dengan pengawasan tidak langsung. Beban kasus memaparkan mahasiswa untuk mengalami kesempatan belajar melalui bekerja dalam kontek kehidupan nyata dengan sekelompok perempuan yang dikenal sepanjang rentang reproduksinya. Perjalanan perempuan yang diikuti mahasiswa akan menumbuhkan rasa percaya diri sebagai pemberi asuhan, memfasilitasi penerapan teori ke dalam praktik, penguasaan keterampilan, berfikir refleksi serta merasa kompeten dalam praktik. ${ }^{13}$

Dari literatur-literatur yang ada, menyatakan kurangnya informasi tentang model pembelajaran klinik dengan beban kasus bagi mahasiswa. Tidak ada bukti yang cukup mengenai ketentuan jumlah kasus dalam memfasilitasi pengalaman belajar keterampilan klinik bagi siswa bidan. ${ }^{14}$

Tujuan penelitian ini adalah untuk menggali pendapat dari mahasiswa, dosen dan bidan pembimbing klinik mengenai model pembelajaran klinik kebidanan yang ideal berdasarkan pengalaman menerapkan model pembelajaran klinik beban kasus selama ini.

\section{METODE}

Penelitian ini merupakan penelitian kualitatif mengacu pada Focus Groups: A Practical Guide for Applied Research ${ }^{15}$, yang digunakan untuk menggali pendapat mahasiswa, dosen dan bidan pembimbing tentang model pembelajaran klinik kebidanan yang ideal untuk mencapai kompetensi asuhan kebidanan pada mahasiswa.

Sejak semester III mahasiswa kebidanan sudah mulai melaksanakan praktik klinik kebidanan (PKK) dengan ditempatkan di tempat bidan praktik mandiri (BPM) yang sebagian besar tersebar di wilayah Kabupaten Boyolali. Pada saat akhir program perkuliahan (semester VI), mahasiswa diundang untuk mengikuti diskusi kelompok terfokus guna menggali pendapat mereka tentang pengalaman pembelajaran praktik klinik kebidanan selama ini dan pendapat tentang model pembelajaran klinik kebidanan yang mereka anggap ideal.

Penelitian ini melibatkan 32 orang dari 76 mahasiswa tingkat akhir Akademi Kebidanan Estu Utomo Boyolali tahun 2013, 14 dosen dan 13 bidan pembimbing klinik dari organisasi profesi (IBI Cabang Boyolali). Seluruh responden adalah mereka yang terlibat dalam program pembelajaran praktik klinik kebidanan Akademi Kebidanan Estu Utomo Boyolali tahun 2012-2013.

Diskusi kelompok dilakukan melalui 3 sesi yang berbeda antara kelompok mahasiswa, dosen dan bidan pembimbing. Ada 4 kelompok mahasiswa, 2 kelompok dosen dan 2 kelompok bidan pembimbing klinik. Jalannya diskusi kelompok terfokus difasilitasi oleh tim peneliti terdiri dari peneliti sendiri dibantu 3 orang tenaga penelitian dengan kualifikasi pendidikan terakhir D4 Bidan Pendidik yang sudah dilatih sebelumnya.

Topik yang dibahas dalam diskusi kelompok terfokus terdiri dari 8 pertanyaan terbuka yang berhubungan dengan pendapat tentang model pembelajaran praktik klinik kebidanan yang ideal untuk pencapaian kompetensi asuhan kebidanan mahasiswa. Topik-topik yang digunakan untuk menstimulasi diskusi kelompok tersebut yaitu:

1. Bagaimana pengalaman belajar melalui praktik klinik dengan model beban kasus selama ini $(50$ asuhan kebidanan bersalin, 100 asuhan kebidanan hamil)? 
2. Bagaimana pendapat saudara tentang model pembelajaran klinik kebidanan beban kasus selama ini bila dikaitkan dengan filosofi asuhan kebidanan?

3. Berapa jumlah kasus yang ideal untuk pencapaian kompetensi asuhan kebidanan mahasiswa?

4. Bagaimana pendapat saudara tentang seting praktik klinik kebidanan yang ideal untuk pencapaian kompetensi asuhan kebidanan mahasiswa?

5. Berapa lama waktu praktik klinik kebidanan untuk pencapaian kompetensi asuhan kebidanan mahasiswa?

6. Bagaimana seharusnya model bimbingan klinik dalam praktik klinik kebidanan?

7. Bagaimana seharusnya dokumentasi asuhan kebidanan dalam pembelajaran praktik klinik kebidanan dibuat?

8. Bagaimana seharusnya metode penilaian terhadap kompetensi praktik klinik kebidanan?

Dua pertanyaan pertama digunakan untuk menggali pendapat tentang model pembelajaran praktik klinik kebidanan dengan beban kasus yang digunakan selama ini. Hal itu untuk menstimulasi gagasan yang diharapkan muncul dari peserta tentang model pembelajaran praktik klinik kebidanan yang ideal 6 pertanyaaan berikutnya).

Diskusi kelompok terfokus direkam dengan tape recorder dan ditranskripsi secara verbatim oleh asisten penelitian. Transkrip dianalisis menggunakan teknik analisis isi secara induktif (inductive content analysis) oleh 3 orang yaitu peneliti, dosen pembimbing praktik klinik, dan asisten peneitian. Sebelumnya dilakukan penjelasan tentang tujuan penelitian dan bagaimana penggunaan software Atlas-Ti versi 6 kepada ketiga orang tersebut. Selanjutnya masing-masing coder bekerja secara independen untuk melakukan analisis transkrip dan membuat koding ke dalam kategori utama yang sesuai (dalam 6 pertanyaan yang diajukan) serta mencoba untuk mengklasifikasikan ke dalam sub-kategori di dalamnya. ${ }^{16}$
Untuk menyelesaikan proses koding, dilakukan pertemuan ketiga orang coder untuk mendiskusikan hasil koding masing-masing sampai mencapai kesepakatan.

Kesimpulan dari hasil analisis disebarkan kepada seluruh partisipan diskusi kelompok terfokus untuk dilakukan pengecekan kebenaran dan keabsahan komentarkomentar yang telah dibuat. Tiga orang asisten penelitian menyebarkan kepada kelompok mahasiswa secara langsung di kelas. Member checking pada kelompok dosen dan pada kelompok bidan pembimbing dilakukan oleh peneliti sendiri secara langsung setelah transkrip selesai ditulis. Rancangan penelitian ini telah mendapatkan persetujuan etik dari Akbid Estu Utomo Boyolali.

\section{HASIL}

Diskusi kelompok terfokus baik dari mahasiswa, dosen maupun bidan pembimbing menghasilkan 1016 isu yang diidentifikasi dari 8 transkrip (4 dari kelompok mahasiswa, 2 dari dosen, dan 2 dari bidan pembimbing). Dari 6 kategori utama yang ditetapkan, setelah dilakukan 3 kali perumusan oleh ketiga coder, maka dapat dilaporkan ringkasan hasil diskusi kelompok terfokus yang disajikan pada Tabel 1 . Beberapa isu penting yang sangat menarik hasil rekaman diskusi kelompok terfokus disebutkan dalam tulisan ini.

Dalam proses pengecekan hasil DKT terhadap peserta hanya ditemukan komentar minor yaitu tentang harapan diubahnya model pembelajaran praktik klinik kebidanan yang berorientasi pada kualitas dibandingkan kuantitas (jumlah kasus). Komentar-komentar tersebut telah diintegrasikan dalam hasil akhir DKT.

Hasil penelitian ini menunjukkan bahwa mahasiswa, dosen maupun bidan pembimbing klinik menginginkan perubahan model pembelajaran klinik yang lebih mengutamakan kualitas daripada kuantitas untuk mencapai kompetensi asuhan kebidanan. Ada enam tema yang diwacanakan oleh mahasiswa, dosen maupun bidan pembimbing klinik tentang model pembelajaran klinik kebidanan yang ideal, yaitu: "target kasus", "durasi praktik klinik", "penempatan klinik”, "bimbingan klinik", dan "dokumentasi laporan”. 
Tabel 1. Isu-isu tentang model pembelajaran kinik kebidanan yang ideal dari perspektif mahasiswa, dosen, dan bidan pembimbing hasil diskusi kelompok terfokus.

\begin{tabular}{|c|c|c|c|c|}
\hline \multirow{2}{*}{ Kategori } & \multirow{2}{*}{ Isu-isu } & \multicolumn{3}{|c|}{ Kelompok } \\
\hline & & Mhs & Bidan & Dosen \\
\hline \multicolumn{5}{|l|}{ Target Kasus } \\
\hline & Kasus nyata di lapangan & 2 & 13 & 8 \\
\hline & Pengurangan jumlah kasus & 38 & 12 & 14 \\
\hline & $\begin{array}{l}\text { Jumlah target kasus disesuaikan masing } \\
\text { masing mahasiswa }\end{array}$ & 11 & 0 & 8 \\
\hline & $\begin{array}{l}\text { Ada target kasus yang komprehensif (askeb } \\
\text { sejak hamil hingga nifas) }\end{array}$ & 1 & 3 & 6 \\
\hline \multicolumn{5}{|c|}{ Durasi praktik klinik } \\
\hline & Penambahan waktu praktik klinik & 25 & 6 & 8 \\
\hline & Minimal 3 bulan tiap sesi PKK & 10 & 8 & 5 \\
\hline \multicolumn{5}{|c|}{ Penempatan Klinik } \\
\hline & Lebih banyak di komunitas (BPM) & 19 & 6 & 4 \\
\hline & Tidak perlu rotasi & 6 & 4 & 1 \\
\hline & 1.2 mahasiswa per bidan & 11 & 5 & 7 \\
\hline \multicolumn{5}{|c|}{ Bimbingan praktik klinik } \\
\hline & Lebih intensif & 21 & 3 & 6 \\
\hline & Diberi kesempatan berlatih & 18 & 4 & 8 \\
\hline & Model kemitraan & 2 & 2 & 10 \\
\hline \multicolumn{5}{|c|}{ Dokumentasi laporan } \\
\hline & Bukti target keterampilan & 14 & 1 & 8 \\
\hline & $\begin{array}{l}\text { Askeb berkelanjutan (dari hamil hingga } \\
\text { nifas) }\end{array}$ & 23 & 6 & 10 \\
\hline & Portofolio/log book & 2 & 0 & 12 \\
\hline \multicolumn{5}{|c|}{ Penilaian praktik klinik } \\
\hline & Penilaian secara obyektif & 22 & 4 & 6 \\
\hline & Penilaian secara langsung di klinik & 6 & 16 & 13 \\
\hline & Penilaian sendiri oleh mahasiswa & 4 & 2 & 7 \\
\hline
\end{tabular}

\section{Target Kasus}

Baik mahasiswa, dosen maupun bidan pembimbing klinik hampir seluruhnya menyatakan bahwa model asuhan kebidanan pada pembelajaran praktik klinik dengan target kasus selama ini sangat memberatkan dan hanya berorientasi pada kuantitas dibanding kualitas. Untuk itu dari ketiga kelompok mengharapkan adanya model pembelajaran klinik kebidanan dengan jumlah kasus tertentu namun cukup bermakna dalam pencapaian kompetensi mahasiswa.

a. Mahasiswa

Mahasiswa menyatakan bahwa model asuhan kebidanan pada pembelajaran praktik klinik dengan target kasus selama ini sangat memberatkan dan hanya berorientasi pada kuantitas dibanding kualitas. Mereka mengharap-kan agar target kasus diturunkan dan kalau memungkinkan disesuaikan dengan kebutuhan masingmasing maha-siswa untuk mencapai kompetensi. Berikut komentar mahasiswa tentang ketidaksetujuannya terhadap model pembelajaran klinik dengan target kasus selama ini:

"Beratus-ratus askeb itu terlalu berlebihan, karena kenyataannya dilahan kan sekali kita praktek itu gak nyampe segitu itu loh.. harusnya menurut sy targetnya gak perlu banyak-banyak disesuaikan dengan kebutuhan masing-masing kita (mahasiswa), misalnya saya cukup dengan melakukan 5 kali ANC udah merasa kompeten (....), tapi yang lain mungkin butuh 10-15 kali..." (Mhs/2/ 2) 
b. Bidan

Kelompok bidan pembimbing menyatakan bahwa model beban kasus yang diterapkan kurang dihayati karena mahasiswa hanya memberikan bukti tulisan (laporan askeb). Mereka mengharapkan agar selama praktik klinik, mahasiswa dibebani dengan kasus nyata di lapangan sebagai bentuk pembelajaran klinik asuhan kebidanan.

“.....Jadi model pembelajaran dengan ngumpulkan askeb kehamilan, persalinan tu pada kenyataannya ndak dihayati, hanya nulis saja nulispun hanya dituliskan orang lain atau foto kopi. ... Mereka (mahasiswa) sebelum lulus itu harusnya betul-betul kompeten di kasus, tidak di model aja tetapi juga pada kasus di lapangan..."(Bdn/ $1 / 1)$

c. Dosen

Disisi lain, dosen pembimbing juga memberikan komentar yang senada tentang ketidaksetujuannya dengan model pembelajaran klinik kebidanan dengan target kasus selama ini. Model pembelajaran klinik kebidanan yang terpotongpotong dalam 3 kali PKK dinilai kurang bermakna dalam menanamkan pemaham-an kepada mahasiswa tentang bagaimana dan seperti apa asuhan kebidanan dijalankan. Mereka mengharapkan adanya model pembelajaran klinik kebidanan dengan memberikan asuhan kebidanan yang sejalan dengan filosofi asuhan kebidanan. “...Sebenarnya sudah lama saya tidak setuju dengan model pembelajaran klinik target kasus saja, karena kenyataannya mahasiswa jarang sekali paling hanya 12 saja yang mencapai target tersebut. Sebaiknya dibuat seperti di Australia tu ya, pembelajaran kliniknya sejalan dengan filosofi asuhan kebidanan pake model continuity of care..." (Dsn/3/1)

\section{Durasi Praktik Klinik}

Dari sisi durasi praktik klinik, seluruh peserta DKT baik dari kelompok mahasiswa, dosen maupun bidan mengusulkan adanya penambahan alokasi waktu di klinik. Setiap periode praktik klinik minimal dialokasikan 3 bulan dengan harapan dapat praktik memberikan asuhan kebidanan secara berkelanjutan terhadap kasus (hamil, bersalin, nifas).

\section{a. Mahasiswa}

Kelompok mahasiswa merasa durasi praktik klinik selama ini masih kurang. Mereka mengusulkan agar lama praktik klinik ditambah agar dapat memberikan asuhan kebidanan kepada setiap kasus secara berkelanjutan dari hamil, bersalin hingga masa nifas.

“....Sangat kurang kalau hanya 1-11/2 bulan, baru mau bisa melakukan satu perasat eh udah ditarik. Minimal ya 3 bulan itu baru bisa memberi asuhan kebidanan secara berkelanjutan sejak hamil (TM III) sampai nifas..."(Mhs/4/3)

b. Bidan dan dosen

Menurut bidan dan dosen, praktik klinik kebidanan minimal selama 3 bulan untuk memfasilitasi keterampilan memberikan asuhan kebidanan secara menyeluruh. Berikut salah satu komentar bidan tentang usulan durasi praktik klinik kebidanan:

“...paling nggak dalam 1 semester itu ada 6 bulan, 3 bulan untuk praktek, 3 bulan untuk teori. Seperti pada waktu jaman saya dulu.. jadi kita melakukan asuhan itu betul-betul tuntas....(Bdn/6/2)

\section{Penempatan Klinik}

a. Mahasiswa

Menurut pendapat mahasiswa, kompetensi asuhan kebidanan akan lebih mudah dicapai bila mereka ditempatkan di bidan komunitas (bidan desa) dan tidak perlu dilakukan rolling (rotasi).

“....: Pengalaman enak itu kalo di bidan desa bu, kita banyak pengalaman macam-macam, karena kita kan sering diajak kunjungan ke rumahrumah, posyandu, selain itu juga ee..bu bidannya itu lebih banyak waktu untuk mendampingi kita kalo pas ANC, menolong persalinan dan kunjungan nifas bu..."(Mhs/5/2)

b. Bidan

Hal yang sama juga disampaikan oleh kelompok bidan pembimbing. 
“... ditempatkan di bidan desa atau bidan praktik mandiri tidak perlu diroling ke rumah sakit, kan butuhnya asuhan fisiologis prinsipnya. ...selama mahasiswa itu menempati disatu tempat ya..tidak berpindah-pindah dalam jangka waktu 3 bulan minimal..” (Bdn/6/2)

c. Dosen

Kelompok dosen menambahkan usulan agar penempatan klinik idealnya 1-2 mahasiswa di setiap bidan desa.

“....idealnya 1-2 mahasiswa di setiap bidan praktik mandiri, dengan begitu mahasiswa akan memperoleh kasus yang memadai dengan bimbingan yang intensif...”(Dsn/1/1)

\section{Bimbingan Praktik Klinik}

a. Mahasiswa

Kelompok mahasiswa sangat mengharapkan bimbingan klinik yang intensif dan lebih banyak diberi kesempatan berlatih keterampilan yang menjadi target kompetensi mereka.

“....dalam praktik klinik kebidanan kita (mahasiswa) mengharapkan bimbingan dari ibu bidan secara intensif..dan sering diberi kesempat-an melakukan sendiri (keterampilan) sambil didampingi gitu...kalo belum benar diberitahu baik-baik...(Mhs/8/4)

b. Dosen

Dari pihak dosen mengusulkan bimbingan dengan model kemitraan, dimana mahasiswa sebagai calon bidan diperlakukan sebagai mitra bidan yang dapat membantu tugas-tugas bidan.

“....mahasiswa kan bisa membantu tugas-tugas bidan, jadi mungkin dengan bimbingan model kemitraan akan lebih membuat mahasiswa merasa nyaman dan diperhitungkan...”(Dsn/5/2)

\section{Dokumentasi Laporan}

a. Mahasiswa

Mahasiswa menghendaki dokumentasi laporan asuhan kebidanan dalam pembelajaran praktik klinik berupa bukti target keterampilan tertentu yang telah kuasai oleh mahasiswa dan beberapa laporan asuhan kebidanan panjang dari kasus yang benar-benar dilakukan. “....meski nulis laporan adalah hal yang paling tidak menyenangkan, tetapi kalau menulis yang benar-benar dikerjakan kan enak, tidak perlu mengarang banyak-banyak... misal askeb bumil A dari hamil sampai bersalin sampai nifaspun gakpapa....sama mungkin bukti pencapaian keterampilan saja kali ya...”(Mhs/7/1)

b. Bidan

Dari kelompok bidan juga mengusulkan bentuk dokumentasi laporan berupa laporan asuhan kebidanan panjang berdasarkan kasus yang telah diberikan asuhan oleh mahasiswa.

"....daripada hanya minta data pasien untuk dibuat laporan palsu, mendingan buat $2 / 3$ laporan askeb panjang dari askeb hamil sampai bersalin sampai nifas itu malah lebih bagus... $(\mathrm{Bdn} / 4 / 1)$

c. Dosen

Kelompok dosen menambahkan dokumen berupa portofolio atau log book, yang dapat digunakan untuk membantu melatih mahasiswa berfikir refleksi.

“....mahasiswa perlu membuat portofolio atau semacam diary, ini akan sangat membantu mahasiswa berfikir refleksi...pengalaman apa yang telah diperoleh, kendala apa yang dihadapi bisa dituliskan disini...”(Dsn/2/2)

\section{Penilaian Praktik Klinik}

a. Mahasiswa

Mahasiswa mengharapkan penilaian klinik yang obyektif bagi masing-masing mahasiswa melalui kontrak evaluasi yang dibuat oleh mahasiswa saat sudah merasa siap dievaluasi.

“....penilaian sebaiknya obyektif satu persatu mahasiswa dilihat pasti beda-beda...kalo pas udah siap dinilai lebih enjoy kan jadi pede..."(Mhs/3/2).

b. Dosen

Dosen mengusulkan bahwa penilaian praktik klinik dengan berbagai cara untuk memotret keseluruhan kompetensi klinik yang dicapai mahasiswa.

“....tidak cukup dengan satu format saja kemudian sudah dianggap nilai keseluruhan (praktik 
klinik)...baiknya penilaian di klinik dengan berbagai cara seperti rubrik, checklist, portofolio dll..."(Dsn/1/1)

Hasil penelitian ini didukung hasil penelitian Rawnson, yang menyatakan bahwa komponen jumlah kasus harus dipersiapkan dengan baik dalam perencanaan pembelajaran praktik klinik yang disesuaikan dengan kebutuhan masing-masing mahasiswa. ${ }^{13}$ Negosiasi dilakukan secara perorangan dalam hubungannya dengan kualifikasi akademik maupun perkembangan personal dan profesional mahasiswa. ${ }^{18}$ Di lain pihak Gray menyatakan bahwa tidak ada bukti yang cukup mengenai ketentuan jumlah kasus dalam memfasilitasi pengalaman belajar keterampilan klinik bagi siswa bidan. ${ }^{14}$

Dari pihak dosen mengusulkan adanya target kasus yang diikuti mahasiswa untuk diberikan asuhan kebidanan sejak hamil, bersalin hingga nifas dimana hal ini sejalan dengan filosofi asuhan kebidanan continuity of care. Sebagaimana pernyataan dari ICM, bahwa guna membekali lulusan agar mampu bekerja berdasarkan filosofi asuhan kebidanan, maka pola pendidikan bidan diharapkan konsisten dengan filosofi asuhan kebidanan. ${ }^{12}$ Continuity of midwifery care (asuhan kebidanan secara terus menerus berkelanjutan), adalah terbangunnya relasi antara seorang perempuan dan bidan untuk bekerjasama secara kemitraan dalam asuhan selama kehamilan, persalinan dan masa nifas (childbearing continuum). ${ }^{19}$ Dengan model ini, siswa diharapkan memperoleh pengalaman secara langsung dalam memberikan asuhan kebidanan yang berkelanjutan pada perempuan dengan jumlah kasus tertentu (30 selama masa studi). ${ }^{20}$

Durasi waktu praktik klinik yang ideal sebaiknya cukup panjang, minimal 3 bulan dalam satu periode praktik klinik. Hal ini selaras dengan sistem pendidikan kebidanan Australia yang menyatakan bahwa pendidikan diploma harus distrukturkan sehingga alokasi waktu praktik klinik lebih lama. ${ }^{21}$ Selain itu mahasiswa diharapkan memperoleh bimbingan dalam kurun waktu yang cukup lama yakni sepanjang rentang masa reproduksi perempuan sejak kehamilan, persalinan hingga masa nifas. ${ }^{14,22}$ Standar yang dikeluarkan ICM bagi penyelenggara pendidikan Kebidanan, menyatakan bahwa mahasiswa membutuhkan pengalaman klinik minimal 1500 jam (ICM, 2010), yaitu sekitar 20 jam per asuhan terhadap perempuan. ${ }^{12}$ Turner dan Walker berpendapat bahwa alokasi waktu yang lama untuk praktik klinik merupakan elemen dalam mengembangkan perasaan diakui (belongingness). ${ }^{23,24}$

Dari perspektif mahasiswa dan bidan pembimbing, penempatan praktik klinik kebidanan sebaiknya di bidan komunitas, dengan pertimbangan tugas-tugas asuhan kebidanan akan lebih banyak dilakukan oleh bidan di komunitas. Hal ini sesuai pendapat Licqurish \& Seibold bahwa asuhan kebidanan yang berkelanjutan terhadap perempuan sejak kehamilan, persalinan dan masa nifas hanya dapat dilakukan oleh bidan yang bekerja di komunitas. ${ }^{21}$ Selain itu mahasiswa diharapkan dapat berada dekat dengan perempuan yang diberikan asuhan serta setiap saat memperoleh bimbingan dari bidan yang mendampinginya. ${ }^{12,22}$ Masih menurut Licqurish \& Seibold, mahasiswa seharusnya ditempatkan di komunitas bersama seorang bidan guna memperoleh pengalaman yang luas, terutama bagaimana mahasiswa belajar menerapkan model asuhan kebidanan berkesinambungan. Jumlah siswa yang dialokasikan untuk sebuah program praktik klinik seharusnya diatur untuk menghindari kelebihan alokasi yang membuat situasi pembelajaran menjadi tidak kondusif. ${ }^{22}$

Pengalaman praktik klinik seharusnya memungkinkan siswa memperoleh kesempatan untuk mengambil tanggung jawab, bekerja secara mandiri serta menerima umpan balik dalam praktik mereka. ${ }^{25}$ Filosofi pendidikan kebidanan seharusnya sejalan dengan filosofi asuhan yang diperlukan dalam pembelajaran klinik melalui pendekatan kemitraan (partnership approach). ${ }^{26}$ Bidan harus bekerja bersama mahasiswa merupakan kebutuhan mendasar yang dapat mempengaruhi apakah mahasiswa akan mengalami kemajuan atau berkembang menjadi praktisi mandiri. ${ }^{27}$ Pembimbing dipersiapkan dengan baik untuk melakukan pendampingan bimbingan (mentorship) dan menciptakan sebuah partnership dalam bekerja. ${ }^{28}$

Pengumpulan bukti dalam kaitannya dengan pengalaman klinis merupakan faktor penting dalam proses pembelajaran. ${ }^{29}$ Salah satu bentuk catatan perkembangan belajar siswa terkait tujuan pembelajaran klinik adalah dalam bentuk portofolio. Sebagai suatu metode pembelajaran, portofolio dapat mencakup 
pekerjaan harian, jurnal kegiatan, catatan belajar yang didukung oleh alasan yang mengacu pada teori maupun hasil penelitian dimana siswa disarankan dengan bentuk yang paling cocok untuk diri mereka sendiri. ${ }^{30}$

Masukan untuk penilaian praktik klinik agar sebaiknya dilaksanakan di klinik dengan mengkombinasikan berbagai metode termasuk penilaian oleh mahasiswa sendiri sebagai bentuk tanggung jawab terhadap kompetensi yang akan dicapai. Kombinasi metode penilaian yang tergambar dalam portofolio (catatan refleksi) serta instrumen penilaian kompetensi diikuti penilaian sendiri oleh siswa dibandingkan dengan penilaian oleh penguji, dapat digunakan untuk meningkatkan reliabilitas penilaian kompetensi. ${ }^{31}$ Penilaian dalam situasi praktik nyata, penilaian dengan simulated patient seluruhnya meningkatkan rasa percaya diri dalam kompetensi siswa. ${ }^{32}$

\section{KESIMPULAN}

Dari enam tema yang dihasilkan dari penelitian ini mengingatkan kembali tentang perencanaan pembelajaran klinik dalam program pendidikan kebidanan. Hal itu tampak jelas dalam keseluruhan tema yang dihasilkan dari persepsi mahasiswa, dosen dan bidan pembimbing kinik. Hasil penelitian ini menunjukkan adanya beberapa kemiripan dengan penelitian-penelitian sebelumnya dan mengkonfirmasi kembali beberapa faktor yang harus dipertimbangkan dalam program pembelajaran klinik kebidanan secara umum.

Pendapat, masukan, dan harapan baik dari mahasiswa, dosen maupun bidan pembimbing memberikan referensi yang sangat berharga untuk program perbaikan model pembelajaran kinik kebidanan. Keseluruhan pernyataan ketiga komponen penting dalam pembelajaran klinik kebidanan ini menginginkan adanya suatu perubahan model pembelajaran klinik yang lebih mengutamakan kualitas dibanding kuantitas.

Hasil penelitian ini akan sangat berguna bagi institusi pendidikan kebidanann dalam merencanakan strategi untuk meningkatkan efektifitas pembelajaran praktik klinik kebidanan. Hasil penelitian juga akan sangat membantu institusi pendidikan dalam merencanakan kurikulum pendidikan kebidanan terutama dalam pembelajaran klinik dengan melibatkan berbagai unsur terkait.

\section{DAFTAR PUSTAKA}

1. Royal College of Nursing. Helping Students Get the Best from Their Practice Placements: A Royal College of Nursing Toolkit. RCN. London, 2002.

2. White R, and Ewan, C.E. Clinical Teaching in Nursing, London, Chapman Hall, 1991.

3. Reilly, D. E. \& Oermann, M. H. Clinical teaching in nursing education (2nd ed.). New York: National League for Nursing, 1992.

4. Tabari Khomeiran, R., Yekta, Z.P., Kiger, A.M. \& Ahmadi, F.Professional competence: Factors described by nurses as influencing their development. International Nursing Review. 2006; 53(1): 66-72.

5. Burns, I. \& Paterson, I.M. Clinical practice and placement support: Supporting learning in practice. Nursing Education in Practice. 2005; 5(1):3-9.

6. Ullrich, S. First birth Stories of student midwives: Keys to professional affective socialisation. Journal of Midwifery \& Women's Health. 2004; 49(5): 390-397.

7. Quinn, FM. The principles and practice of nurse education. 3rd edition. Cheltenham: Nelson Thornes, 2001.

8. Levett Jones, T., Lathlean, J., McMillan, M. and Higgins, I. Staff student relationships and their impact on nursing students' belongingness and learning. Journal of Advanced Nursing, 2012; 26 (2).

9. Page, L.A. One-to-one midwifery: Restoring the "with woman' relationship in midwifery. Journal of Midwifery \& Women's Health Online, 2003; 48.

10. Depkes RI. Kurikulum Pendidikan D-III kebidanan. Jakarta: Depkes RI, 2002.

11. Sofyan, Mustika. 50 Tahun Ikatan Bidan Indonesia Bidan Menyongsong Masa Depan, PP-IBI. Jakarta, 2006.

12. International Confederation of Midwives (ICM). Global Standards for Midwifery Education. (Internet) 2011 (cited 2012 April 22). Available from: www.internationalmidwives.org/Documentation/ ICMGlobalStandardsCompetenciesandTools/

13. Rawnson S., Fry J., Lewis P. Student caseloading: embedding the concept within education. BJM. 2008; 16(10): 636-41.

14. Gray J., Leap N., Sheehy A., Homer C.S.E. The 'follow-through' experience in three-year Bachelor of Midwifery programs in Australia: A survey of students. Nurse Education in Practice. 2012; 12: 258 263.

15. Krueger RA: Focus Groups: A Practical Guide for Applied Research. Sage Publications: California. 1988. 
16. Elo S, Kyngäs $\mathrm{H}$ : The qualitative content analysis process. J Adv Nurs. 2008; 62:107-115.

17. Fraenkel JR, Wallen NE: How to Design and Evaluate Research in Education. 8th edition. New York: McGraw-Hill, 2009; 485-494.

18. Rawnson S., Fry J., Buxton C., Woolfenden E. Looking to the future: but starting now! [Workshop report] MIDIRS Midwifery Digest, 2005; 15(suppl 2): S19-S21

19. Australian College of Midwives (ACM). ACM Philosophy for Midwifery. (Internet). 2007. (cited 2012 maret 21). Availabel from: http://www. mid wives.org.au/AboutUs/ACM Philosophy for Midwifery/tabid/256/Default.aspx

20. Seibold, C. The experiences of a first cohort of Bachelor of Midwifery students, Victoria, Australia. Australian Midwifery Journal. 2002; 18(3): 9 -16.

21. Australian Senate. The patient profession: time for action. Report of the review of the Senate Community Affairs Committee on the Inquiry into Nursing 2002. (Internet). 2006. (cited 2012 Des 20). Availabel from: http://www.apa.gov.au/senate/committee/clac_ctte/ nursing/report/contents.html

22. Licqurish, S. \& Seibold, C. Bachelor of Midwifery students' experiences of achieving competencies: The role of the midwife preceptor. Midwifery. 2008; 24(4): 480-489.

23. Turner, C., Davies, E., Beattie, H., Vickerstaff, J. and Wilkinson, G. Developing an innovative undergraduate curriculum: responding to the 2002 National Review of Nursing Education in Australia. Collegian. 2006; 13(1):5 12 .
24. Walker, K. Postmodern pedagogy and the nursing curriculum: collaborating for excellence. Collegian. 2005; 12(4):36 40.

25. Löfmark, A. Carlsson, M. Wikblad, K. Student nurses' perception of independence of supervision during clinical nursing practice. Journal of Clinical Nursing. 2001; 10: 86-93.

26. Potgieter, E, Dürrheim, M \& Du Toit, HS. Only Study Guide for Health Sciences Education. HSE201-P. Pretoria: University of South Africa. 2000.

27. Myrick, F. \& Yonge, O. Enhancing critical thinking in the preceptorship experience in nursing education. Journal of Advanced Nursing. 2004; 45(4): 371-380.

28. Royal College of Nursing. Guidance for mentors of nursing students and midwives. A Royal College of Nursing Toolkit. RCN, London. 2009.

29. Stuart CC. Assessment, supervision and support in clinical practice. $2^{\text {th }}$ ed. Edinburgh: Churchill Livingstone. 2007.

30. Howarth, A. The portfolio as an assessment tool in midwifery education. British Journal of Midwifery. 1999; 7(4):.327-329.

31. McMullan, M. R., Endacott, R., Gray, M.A., Jasper, M., Miller, C.M.L., Scholes, J. \& Webb, C. Portfolios and assessment of competence: a review of the literature. Journal of Advanced Nursing. 2003; 41(3): 283-294.

32. Norman, J., Watson, R., Murrells, T., Calman, L., \& Redfern, S. The validity and reliability of methods to assess the competence to practise of pre-registration nursing and midwifery students. International Journal of Nursing Studies. 2002; 39(2): 133-145. 